Volume 6, No. 3

July - September 2020

www.jrmi.pk

\title{
Risk factors associated with postpartum depression in two tertiary care hospitals of Peshawar: a comparative cross-sectional study
}

Hira Bakhtiar, Maria Malik A. Khaliq, Asif Nawaz, Muhammad Asif, Siraj Jamil, Shahzad Jamal, Muhammad Usman, Naveed Alam

\section{Submitted}

July 20, 2020

Accepted

August 10, 2020

\section{Author Information}

From: Rehman Medical Institute (RMI), Peshawar, Khyber Pakhtunkhwa, Pakistan.

Dr. Hira Bakhtiar

House Officer

(Corresponding Author)

Email:

hira.bakhtiar@rmi.edu.pk

Dr. Maria Malik A. Khaliq

Dr. Asif Nawaz

Dr. Muhammad Asif

Dr. Siraj Jamil

Dr. Shahzad Jamal

Dr. Muhammad Usman

Dr. Naveed Alam

House officers, RMI

Citation: Bakhtiar H, Khaliq MMA, Nawaz A, Asif M, Jamil S, Jamal S, et al. Risk factors associated with postpartum depression in two tertiary care hospitals of Peshawar: a comparative cross-sectional study. J Rehman Med Inst. 2020 JulSep;6(3):16-9.

\begin{abstract}
Introduction: Postpartum depression has become a common complication in women in their postpartum period, affecting not only the mother but her child and her family. Due to lack of awareness regarding the subject it has been widely neglected, especially in Pakistan.
\end{abstract}

Objective: To determine and compare the frequency and risk factors associated with postpartum depression in a public and a private tertiary care hospital in Peshawar.

Materials \& Methods: A comparative cross-sectional study was conducted in the Gynecology and Pediatrics OPD and Pediatrics ward of Rehman Medical Institute (RMI) and Gynecology and Pediatrics OPD as well as the vaccination center of Hayatabad Medical Complex (HMC) over a period of 6 months (January to June 2016). The women were interviewed after obtaining informed consent during 1-12 months of thei postpartum period using the Edinburgh Postnatal Depression Scale (EPDS) as well as a pretested selfstructured questionnaire. Chi Square test and binary logistic regression were used to determine the relative significance of various risk factors for PPD.

Results: A total of 280 women were interviewed, 140 in each hospital, their ages ranging from 16 to 45 years The frequency of PPD calculated at RMI was $62.7 \%$ and at $\mathrm{HMC}$ it was $37.3 \% \quad(\mathrm{p}=0.001)$. Risk factors that showed a close association with PPD included the leve of education of women $(\mathrm{p}=0.008)$, family support $(\mathrm{p}=0.022)$, and history of previous trauma $(\mathrm{p}=0.055)$

Conclusion: Postpartum depression is twice as likely to occur in a private tertiary care hospital compared to a public one, and appears related to educational status, family help, and history of trauma.

Keywords: Depression, Postpartum; Postpartum Period, Mothers; Child; Breast Feeding; Childbirth.

The authors declared no conflict of interest. All authors contributed substantially to the planning of research, data collection, data analysis, and write-up of the article, and agreed to be accountable for all aspects of the work.

\section{INTRODUCTION}

Postpartum depression (PPD) is defined as an episode of non-psychotic depression within 1 year of childbirth. ${ }^{1}$ It may present as a continuation of postpartum blues (mood swings, crying spells, anxiety and difficulty sleeping), which occur typically in the first 4 weeks after giving birth. ${ }^{2}$

Among chronic diseases, depression places the second greatest burden on women's health worldwide. ${ }^{3}$ The prevalence of major depressive disorders in women increases during their reproductive years, as women are more likely to suffer from mood and anxiety disorders following childbirth than at any other time in their lives. ${ }^{4}$

Globally, prevalence of PPD ranges from almost $0 \%$ in Singapore to nearly $57 \%$ in Brazil..$^{5}$ The prevalence of PPD in Pakistan ranges from 24\% $42 \%$ in urban tertiary care settings and $28 \%-36 \%$ in rural settings. ${ }^{4} \mathrm{~A}$ recent study shows Pakistan has a prevalence rate of $28 \%-63 \% .^{6}$ An South Indian survey showed a prevalence of $31.4 \%$ (the postpartum period dated from $4^{\text {th }}$ week of lactation to the $10^{\text {th }}$ week). ${ }^{7}$ The variability in reported PPD globally might be due to cross-cultural variables, reporting style, differences in perception of mental health and its stigma, differences in socioeconomic environments (e.g. poverty, levels of social support or its perception, nutrition, stress), and biological vulnerability factors.

Women experiencing PPD appear to be unhappy, irritable, and unable to cope; have negative feelings about themselves and their children; are anxious; experience difficulties managing household tasks; have physical symptoms, such as sleep and appetite disturbances; and display obsessional behavior. ${ }^{9}$ PPD usually goes unrecognized because of its resemblance with puerperal symptoms (like fatigue, loss of libido and sleeping disorders). ${ }^{10}$

Risk factors linked to development of PPD include age of the mother, history of previous traumatic experiences and illiteracy. ${ }^{11}$ Socio-economic status also plays a role; studies show that it is three times more likely to occur in developing countries than developed countries. ${ }^{12}$ 
An association has been found in some regions between PPD and whether the child was conceived intentionally or not. ${ }^{13}$ Breastfeeding generally has shown that it is negatively associated with PPD, being known to decrease its incidence. ${ }^{14}$

Findings also have indicated that females in the postpartum period are prone to develop PPD if they lack emotional support, instrumental support, informational support or social support in general. ${ }^{15}$ Further research has shown that experiencing symptoms of PPD can have immediate ill effects on the offspring. ${ }^{16}$ Additionally, marital stress and the lack of prenatal care have both been associated with a higher risk of PPD symptomatology. ${ }^{17}$

Studies show that previous history of depressive episodes does predispose women significantly to PPD. ${ }^{18}$ Despite the various studies done for defining the risk factors for PPD throughout the world, the results have been inconsistent and vary in between regions. Pakistan's recent data on PPD is limited and provides a wide basis for further research.

Therefore, this study was conducted to determine the magnitude and risk factors for PPD in the city of Peshawar, so that awareness regarding these variables and their levels of association can be spread.

\section{MATERIALS \& METHODS}

A comparative cross sectional study was conducted by collecting data from the Gynecology and Pediatrics Outpatients Departments of Rehman Medical Institute (RMI) and Hayatabad Medical Complex (HMC), Pediatric wards of RMI, and the vaccination center of HMC over a period of 6 months (January to June 2016). RMI is a private tertiary care hospital possessing a bed capacity of 640 whereas HMC is a public sector tertiary care hospital with a bed capacity of 1280. Convenience sampling was done for the calculated sample size of 280 subjects using the WHO Sample Size formula $\left(n=z^{2}(p \times q) / d^{2}\right)$, taking 140 each from RMI and HMC. Only those women were included who were 1-12 months postpartum and above the age of 15 years, whereas women with history of stillbirth and major depressive disorder were excluded. Data were collected after informed consent from all subjects.

The variables known to have an association with development of postpartum depression were included in the study. These included age, location, level of education of mothers, their family systems, their employment status, the number of children they had, whether they breastfed their babies or not, whether the child was unplanned, history of traumatic experience, family support, monthly household income, quality of marriage, infants' gender, preterm birth of child, and whether the child was born with special needs. These variables were studied using a pretested self-structured questionnaire and a self-translated Pashto version of Edinburgh Postnatal Depression Scale (EPDS). The EPDS has 3 marks per question for a total score of 30 for 10 questions; the standard cut off point for depression (score of 13) was used in the study and correlated with different risk factors.

Since the women were accompanied by their in-laws or husbands, they could not answer freely at many instances, therefore there may have been some information bias. Data were analyzed using SPSS version 25. Crosstabs were used to compare the prevalence of postpartum depression in RMI and HMC. The Chi Square test was used to test the strength of association between the presence of PPD and the hospitals where the study was conducted, maintaining $\mathrm{p} \leq 0.05$ as significant. Binary logistic regression analysis was used to test the significance of association between PPD and associated risk factors.

\section{RESULTS}

A total of 280 women were interviewed according to the study criteria. The ages of the women ranged from 16 to 45 years; $56.1 \%$ women were from urban areas whereas $43.9 \%$ came from rural areas; 140 were interviewed at RMI and similarly, 140 at HMC. The frequency of PPD at RMI was found to be $62.7 \%$ and $37.3 \%$ at HMC $(\mathrm{p}=0.001)$ as shown in Table 1 .

Table 1: Prevalence of depression among female subjects $(\mathbf{n}=280)$.

\begin{tabular}{|l|c|c|c|}
\hline \multicolumn{1}{|c|}{ Status } & HMC & RMI & p value \\
\cline { 1 - 3 } Depressed & $37.30 \%$ & $62.70 \%$ & \multirow{2}{*}{0.001} \\
\cline { 1 - 3 } Not depressed & $57.10 \%$ & $42.90 \%$ & \\
\hline
\end{tabular}

Binary Logistic Regression Analysis showed that the development of Postpartum Depression in these women was associated with educational status of the woman $(p=0.008)$, Family support $(p=0.022)$, and Past trauma $(p=0.055)$. This can be observed in Table 2 below:

Table 2: Development of PPD based on known risk factors in female subjects $(n=280)$.

\begin{tabular}{|l|c|c|c|c|}
\hline \multirow{2}{*}{ Variables } & \multirow{2}{*}{$\begin{array}{c}\text { Odds } \\
\text { Ratio }\end{array}$} & \multicolumn{2}{|c|}{$95.0 \%$ C.I. } & \multirow{2}{*}{ p value } \\
\cline { 3 - 4 } & 0.974 & 0.917 & 1.035 & 0.402 \\
\hline Age & 0.693 & 0.34 & 1.411 & 0.312 \\
\hline Location & 1.902 & 0.849 & 4.264 & 0.118 \\
\hline Family system & 0.681 & 0.512 & 0.905 & $\mathbf{0 . 0 0 8}$ \\
\hline Education & 0.471 & 0.135 & 1.645 & 0.238 \\
\hline Job & 0.915 & 0.684 & 1.225 & 0.552 \\
\hline No. of children & 0.705 & 0.285 & 1.744 & 0.449 \\
\hline Planned child & 1.711 & 0.775 & 3.78 & 0.183 \\
\hline Breastfeeding & 1.156 & 0.922 & 1.45 & 0.208 \\
\hline Income & 0.719 & 0.38 & 1.362 & 0.312 \\
\hline Marriage & 0.434 & 0.212 & 0.89 & $\mathbf{0 . 0 2 2}$ \\
\hline Family help & 2.367 & 0.98 & 5.719 & $\mathbf{0 . 0 5 5}$ \\
\hline Past Trauma & 1.077 & 0.561 & 2.068 & 0.822 \\
\hline Child gender & 0.962 & 0.209 & 4.422 & 0.96 \\
\hline Term & 2.172 & 0.952 & 4.959 & 0.065 \\
\hline Special needs & & & & \\
\hline
\end{tabular}

On the other hand, no significant association was observed between presence of PPD and location $(p=0.693)$, their ages $(p=0.974)$, their family systems $(p=1.902)$, their employment status $(p=0.471)$, the number of children they had $(p=0.915)$, 
and whether they breastfed their babies or not $(p=1.711)$. Similarly, no remarkable association was found between PPD and the monthly household income $(p=1.156)$, quality of marriage $(p=0.719)$ or infants' gender $(p=1.077)$; Neither did the fact that their infant was unplanned $(p=0.705)$, born pre term $(p=0.962)$ or with special needs $(p=2.172)$ had significant bearing on the prevalence of PPD, also shown in Table 2.

\section{DISCUSSION}

According to this study a higher level of Postpartum Depression was found in RMI, a private institute $(62.7 \%)$ than in HMC, a public institute (37.3\%). A study conducted previously in HMC in $2014,{ }^{18}$ showed PPD to be in $30 \%$ of female subjects. Another study conducted in Islamabad in 2017 showed PPD to be $17.3 \%,{ }^{19}$ whilst a study conducted in India showed it to be $18 \%,{ }^{20}$ and another on Lebanese women showed a figure of $33.3 \% .^{21}$

Among all the studied risk factors, three showed close association with development of postpartum depression, namely family support, level of education, and previous trauma; however, it is difficult to attribute these factors as accountable for the high difference in occurrence of PPD between these two hospitals, since RMI mostly receives well educated patients from high socio-economic backgrounds where these factors should be in play to decrease PPD.

The study showed that those who received family help with childcare had a lesser incidence (54\% depressed to $78.5 \%$ nondepressed) of developing PPD compared to those who did not receive any help (45\% depressed to $21.5 \%$ non-depressed). Such results have also been reported in studies conducted in Canada ${ }^{22}$ where the risk of PPD was seen to be closely associated with reduced family support after childbirth, same results were observed in the study conducted over Lebanese women where $21.1 \%$ woman without family support showed signs of PPD. ${ }^{21}$ Studies conducted on Japanese ${ }^{23}$ and Indian women ${ }^{24}$ showed the same association as well as in a study conducted in Karachi. ${ }^{10}$

The study also indicated that those with no education were more depressed (43.9\%) compared to those who had received primary education (15.3\%), secondary education (18.4\%), were completing or had completed a bachelor's degree $(10.2 \%)$ or master's degree (12.2\%). The same association has been observed in studies conducted in Karachi, ${ }^{6,10}$ and Iran. ${ }^{11}$

The study further showed that those with a previous traumatic experience showed a higher incidence of PPD (22.2\% depressed versus $12.1 \%$ non-depressed) as compared to those who had not (77.8\% depressed to $87.9 \%$ non-depressed). A study conducted in Fatima Hospital of Baqai Medical University Karachi ${ }^{6}$ also showed a strong correlation of traumatic stress with development of postpartum depression. Another study conducted in Karachi also showed a significant association between past traumatic experiences and PPD. ${ }^{10}$

Even though previous studies have shown an association between age, monthly household income and preterm delivery, ${ }^{8,10}$ results of the current study have been contradictory to it.

\section{CONCLUSION}

Postpartum Depression occurred almost twice as frequently in a private tertiary care hospital of Peshawar, Khyber Pakhtunkhwa, Pakistan, compared to a similar level public hospital. Factors such as level of education, family support, and previous traumatic experiences had a significant association with development of PPD.

\section{RECOMMENDATIONS}

Measures should be taken by the government to spread awareness regarding the disease and counsel family members to support females who develop postpartum depression. Efforts should be made to improve the educational status of women to make them more self-reliant and aware.

\section{LIMITATIONS}

Temporal sequence of events cannot be established. Information bias may have been involved as the women were mostly accompanied by their in-laws or husbands, therefore they could not answer freely enough.

\section{GENERALIZABILITY}

The results of our study can be applicable to other tertiary care hospitals of the province/country since the general characters of the patients and health care services remain the same throughout.

\section{REFERENCES}

1. Robertson E, Celasun N, Stewart DE. Risk factors for postpartum depression. Chapter 1. In: Stewart DE, Robertson E, Dennis CL, Grace SL, Wallington T. Postpartum depression: Literature review of risk factors and interventions. Toronto, Ontario, Canada: University Health Network Women's Health Program. 2003. Pp.9-70. [Accessed September 04, 2018]. Available from: http://www.who.int/mental_health/preve ntion/suicide/lit_review_postpartum_dep ression.pdf.

2. Leitch S. Postpartum depression: A review of the literature. St. Thomas,
Ontario: Elgin-St. Thomas Health Unit. 2002 Dec;2.

3. World Health Organization. The world health report 2002: reducing risks, promoting healthy life. World Health Organization; 2002.

4. Khanam M, Sultana A, Siddiqui SH, Rehman K. Screening for postpartum depression in recently delivered mothers. Pak J Med Sci. 2011 Apr 1;27(2):320-4.

5. Halbreich U, Karkun S. Cross-cultural and social diversity of prevalence of postpartum depression and depressive symptoms. J Affect Disord. 2006 Apr 1;91(2-3):97-111.

6. Gulamani SS, Shaikh K, Chagani J. Postpartum depression in Pakistan. Nurs Women Health. 2013 Apr 1;17(2):14752.

7. Shivalli S, Gururaj N. Postnatal depression among rural women in South India: do socio-demographic, obstetric and pregnancy outcome have a role to play? PLoS One. 2015 Apr 7;10(4):e0122079.

8. Emmanuel A, Mazhar S, Shahid A. Predictors of postpartum depression 
among Pakistani women delivering in a tertiary care hospital. JSOGP. 2011:3340.

9. Çak HT, Karabekiroğlu K, Kültür EC, Tarakçıŏglu MC, Kaya R, Say GN, et al. Relationship between psychiatric symptoms in expectant parents and postpartum depression and infantile colic: a multicenter follow-up study. Turk Psikiyatri Derg. Summer 2015;26(2):87-98.

10. Ali NS, Ali BS, Azam IS. Post-partum anxiety and depression in peri-urban communities of Karachi, Pakistan: a quasi-experimental study. BMC Public Health. 2009 Dec 1;9(1):384.

11. Mazaheri MA, Rabiei L, Masoudi R, Hamidizadeh S, Nooshabadi MR, Najimi A. Understanding the factors affecting the postpartum depression in the mothers of Isfahan city. J Edu Health Promot. 2014;3:65.

12. Brito $\mathrm{CN}$, Alves SV, Ludermir $\mathrm{AB}$, Araújo TV. Postpartum depression among women with unintended pregnancy. Rev Saude Publica. 2015;49:33

13. Figueiredo $B$, Canário $C$, Field $T$. Breastfeeding is negatively affected by prenatal depression and reduces postpartum depression. Psychol Med. 2014 Apr;44(5):927-36.
14. Afzal S, Khalid R. Social support and postnatal depression in Pakistani context. PJSCP. 2014;12(1):34-8.

15. Kavanaugh M, Halterman JS, Montes G, Epstein M, Hightower AD, Weitzman M. Maternal depressive symptoms are adversely associated with prevention practices and parenting behaviors for preschool children. Ambul Pediat. 2006 Jan 1;6(1):32-7.

16. Morrow M, Smith JE, Lai Y, Jaswal S. Shifting landscapes: immigrant women and postpartum depression. Health Care Women Int. 2008 Jun 25;29(6):593-617.

17. Davey HL, Tough SC, Adair CE, Benzies KM. Risk factors for sub-clinical and major postpartum depression among a community cohort of Canadian women. Matern Child Health J. 2011 Oct 1;15(7):866-75

18. Afridi F, Batool I, Jabbar S, Hassan L, Shinwari K. Frequency of postnatal depression at a tertiary care hospital. J Med Sci. 2014 Mar 3;22(1):35-8.

19. Shah S, Lonergan B. Frequency of postpartum depression and its association with breastfeeding: A cross-sectional survey at immunization clinics in Islamabad, Pakistan. Pakistan. J Pak Med Assoc. 2017 Aug 1;67(8):1151-6.

20. Suguna A, Naveen R, Surekha A. Postnatal depression among women attending a rural maternity hospital in
South India. Natl J Community Med. 2015;6(3):297-301

21. Teissedre F, Chabrol H. Étude de l'EPDS (Échelle postnatale d'Edinburgh) chez 859 mères: dépistage des mères à risque de développer une dépression du postpartum. L'Encéphale. 2004 Sep 1;30(4):376-81. English Abstract available from: https://www.researchgate.net/publication /229218658_Etude_de_l'EPDS_Echelle postnatale_d'Edinburgh_chez_859_meres _depistage_des_meres_a_risque_de_dev elopper_une_depression_du_postpartum. [Accessed September 05, 2018].

22. Lanes A, Kuk JL, Tamim H. Prevalence and characteristics of postpartum depression symptomatology among Canadian women: a cross-sectional study. BMC Public Health. 2011 Dec 1;11(1):302.

23. Takahashi Y, Tamakoshi K. Factors associated with early postpartum maternity blues and depression tendency among Japanese mothers with full-term healthy infants. Nagoya J Med Sci. 2014;76:129-38

24. Gupta S, Kishore J, Mala YM, Ramji S, Aggarwal R. Postpartum Depression in North Indian Women: Prevalence and Risk Factors. J Obstet Gynaecol India. 2013 Aug; 63(4): 223-9. 